\title{
Foray foraging behavior: seasonally variable, food-driven migratory behavior in two calanoid copepod species
}

\author{
James J. Pierson ${ }^{1, *}$, Bruce W. Frost ${ }^{2}$, Andrew W. Leising ${ }^{3}$ \\ ${ }^{1}$ University of Maryland Center for Environmental Sciences (UMCES), Horn Point Laboratory, Cambridge, Maryland 21613, USA \\ ${ }^{2}$ University of Washington, School of Oceanography, Seattle, Washington 98105, USA \\ ${ }^{3}$ NOAA Southwest Fisheries Science Center, Environmental Research Division, Pacific Grove, California 93950, USA
}

\begin{abstract}
We tested a hypothesis we termed 'foray foraging', which states that zooplankton make repeated short-term and short-distance migrations between food-rich surface layers and deeper layers throughout the night. Ultimately, the reason for the behavior is to balance the necessity of feeding with the predation risk in surface waters. We tested the hypothesis on 2 species of marine copepods, Calanus pacificus and Metridia pacifica, in Dabob Bay, Washington, USA. Zooplankton nets and traps were used to collect females of both species from specific layers and while migrating up into and down out of the surface mixed layer to determine turnover rates in the surface layer. Gut contents of individuals were measured to determine if feeding history varied between individuals caught migrating upward and downward or in different layers. Turnover rates of the surface layer were highly variable, ranging from near zero to over $1000 \%$, and were higher in summer and autumn than in spring for both species. Gut contents were consistently higher in animals migrating downward than in those migrating upward, but overall gut contents were higher in spring than in summer or autumn. These results suggest that foray behavior varies in magnitude seasonally and occurs throughout the year for both species but is most pronounced for $M$. pacifica. These findings suggest that vertical migration behaviors occurring in periods shorter than diel scales may affect zooplankton population dynamics through feeding and predation and likely impact the flux of energy and material into and out of the surface mixed layer.
\end{abstract}

KEY WORDS: Foraging behavior · Vertical migration · Calanus pacificus · Metridia pacifica · Gut contents

\section{INTRODUCTION}

Studies of diel vertical migration (DVM) in marine zooplankton often rely on periodic sampling of the vertical distribution of populations using nets, acoustic backscatter, or optical sensing of the distribution of biomass. These data, when combined with simultaneously collected environmental data, have contributed greatly to the understanding of proximate controls on zooplankton vertical distribution, including light (reviewed in Cohen \& Forward 2009) and feeding (reviewed in Pearre 2003). However, as noted by Pearre (2003), the effect of individual behavior and condition on the observed distribution patterns is rarely studied, even though it is those behaviors that led to the population distributions we study. This is essentially a problem of scale; while it is possible to track the movements (over 10 to $1000 \mathrm{~m}$ ) of individual large pelagic organisms ( 0.1 to $10 \mathrm{~m}$ in length; e.g. Block et al. 2011), the small size of zooplankton does not allow for use of the same methods. Most of the studies on zooplankton DVM have relied on comparisons of vertical distributions at different time points to quantify aspects of the behavior. 
Instantaneous pictures of vertical distributions obtained by net sampling over time may provide confounding information. For example, in Dabob Bay (Puget Sound, Washington, USA), multiple studies have reported that the nighttime depth of maximum abundance for Calanus pacificus adult females is often found below the chl a maximum depth (Frost 1988, Osgood \& Frost 1994b, Dagg et al. 1998, Pierson et al. 2005); however, females in that abundance maximum have amounts of chl a similar to those found within the shallower chl a maximum layer (Dagg et al. 1998). In contrast, Metridia pacifica females are often but not always found deeper than the chl a maximum (Osgood \& Frost 1994b, Dagg et al. 1998, Halsband-Lenk 2005), but the individuals in the chl a maximum layer have higher gut chl a concentrations than those in deeper water (Dagg et al. 1998).

These observations likely result from seasonally varying and species-specific foraging and migratory behaviors of these 2 copepod species. In Dabob Bay, Calanus pacificus has been observed to vary its vertical migration pattern over a seasonal cycle (Frost 1988). In spring, adult females have 2 behavioral modes: they may be strongly migratory, or they may remain in the upper 50 to $75 \mathrm{~m}$ both day and night. There were no differences in egg production rates or the fractions of females spawning between females collected in the food-rich uppermost layer and those in the layer immediately below (Pierson et al. 2005a). Regardless of behavioral mode, when females were near the surface, a significant portion, often a majority, of the population occupied a subsurface stratum well below the layer of maximum phytoplankton concentration (Pierson et al. 2005b). This apparent lack of co-location of copepods with abundant phytoplankton raises the question of how female C. pacificus obtain an adequate daily ration, as they clearly do (Dagg et al. 1989, 1997). In summer, DVM patterns differed. Females always performed DVM and, rather than being broadly dispersed in the upper layer, strongly aggregated in the upper $10 \mathrm{~m}$ at night (Frost 1988). During this time in Dabob Bay, stratification is strong and phytoplankton concentration is low and dominated by smaller $(<10 \mu \mathrm{m})$ cells (Frost 1988, Horner et al. 2005) compared to spring and fall. Egg production rates of females are typically very low in summer (Frost 1988, Pierson et al. 2005a). In autumn, C. pacificus females always exhibited DVM but were also broadly distributed when near the surface (Frost 1988). In winter, the C. pacificus population comprises fifth-stage copepodites that are dormant and that remain deeper than $75 \mathrm{~m}$ (Osgood \& Frost 1994a).
For Metridia pacifica, the observations in Dabob Bay are strikingly different. Adult females of $M$. pacifica exhibit DVM behavior year-round, and their vertical distribution is frequently bimodal at night, with one abundance peak in the near-surface water and another at depth (Bollens et al. 1993, Osgood \& Frost 1994b, Hays et al. 2001). This suggests individual behavioral flexibility with either of the 2 distinct behavioral types. Individuals may make migrations on longer than $1 \mathrm{~d}$ periodicity or over a shorter term (within a night) with intermittent excursions between the surface and very deep layers (Hays et al. 2001). The patterns of nocturnal vertical distribution and gut pigments observed by Dagg et al. (1998) were interpreted to suggest that female $M$. pacifica ascend to the surface, feed, and then descend continuously into very deep water. Mackas \& Bohrer (1976) inferred similar behavior for the North Atlantic congener M. lucens.

The observed variation in nighttime vertical distribution and migration behavior of adult female copepods may be the result of behavioral responses of copepods on time and length scales shorter than the canonical DVM behavior. We have termed this 'foray foraging' behavior, and it describes the movements of individuals between food-rich surface waters and the water immediately below. We hypothesize that these forays (1) are driven by a need to balance hunger and predator avoidance, (2) occur throughout the nighttime period (Pierson et al. 2009), (3) are likely to vary between species and season, and (4) are dependent on the distribution and composition of the available food as well as other environmental conditions. This is a modification of the 'hunger/satiation hypothesis', reviewed by Pearre (2003), which states that zooplankton migrate upward to near-surface waters from depth to feed and, once sated, return to deeper waters. The foray foraging hypothesis put forth here is similar except we hypothesize that the individuals may not return to their daytime depths but instead move short distances downward out of the surface waters and then return to surface waters to feed again, with this pattern repeated throughout the night. The final descent to depth at dawn is hypothesized to be synchronous, as has been described for DVM.

We previously observed forays for females of both of our target species, and the primary means of discerning the behavior is a suite of observations obtained by trapping zooplankton and examining the gut contents of individuals moving in different directions (Pierson et al. 2009). In the present study, we determine the seasonal variability in these behav- 
ioral patterns for these 2 species in Dabob Bay to assess the ubiquity of the foray behavior.

\section{MATERIALS AND METHODS}

The goal of this project was to determine how near-surface, nighttime migratory patterns of adult female copepods differ between seasons in relation to varying environmental conditions. We conducted 9 cruises over varying seasons, collected samples with a variety of instruments, and took a wide variety of measurements. Here, we primarily report on the results of 4 of those cruises (see Table 1). The goal of the other cruises was mainly to develop the equipment and methods used in the study presented here (Pierson et al. 2009). All data for this project were collected at a station in Dabob Bay, Puget Sound, Washington, USA $\left(47^{\circ} 46.14^{\prime} \mathrm{N}, 122^{\circ}\right.$ $\left.50.10^{\prime} \mathrm{W}\right)$. Dabob Bay is a fjord, approximately 15 $\mathrm{km}$ long and $5 \mathrm{~km}$ wide, with a maximum depth of $190 \mathrm{~m}$ and a $120 \mathrm{~m}$ sill at the mouth. Our station was located in $175 \mathrm{~m}$ of water at the northern end of the bay. On each cruise, we moored our vessel, the RV 'Clifford A. Barnes', to a buoy installed by the US Navy, and we remained at the mooring for the duration of each cruise. Sampling to test the foray hypothesis was conducted on 2 consecutive nights on each cruise.

\section{Sampling}

Upon arrival at the mooring on each cruise, we first performed a cast with a conductivity-temperaturedepth (CTD) instrument to characterize the water column. The CTD (Sea-Bird 911 plus fitted with a General Oceanics rosette that held twelve $10 \mathrm{l}$ General Oceanics Niskin bottles) had additional sensors to measure chl a fluorescence (WetStar), light transmission (SeaTech), and dissolved oxygen (Sea-Bird 43). On this initial CTD cast, we collected water samples from 12 depths in the upper $50 \mathrm{~m}$ of the water column to measure size-fractionated (whole water and $>10 \mu \mathrm{m}$ ) extracted chl a using EPA method 445.0 (Arar \& Collins 1997). Additional CTD casts were performed at irregular intervals throughout each cruise to examine whether the water column structure changed appreciably over time. The CTD data were used to determine the trap depths. Trap depths were chosen so that they were 1 to $3 \mathrm{~m}$ below the layer of maximum chl a concentration, as determined by the CTD fluorometer data.
Our copepod sampling program involved 2 primary operations: trapping migrating zooplankton and conducting vertically stratified net tows. These operations were performed in concert, except for certain sets of vertical net tows that were done separately from the trapping to characterize the vertical distribution of copepods throughout the entire water column. Our trapping methods and equipment have been described in detail previously (Pierson et al. 2009) but will be briefly noted here, particularly in relation to the vertical net tows. Each trapping event was considered a 'series', which consisted of a 45 min-long deployment of the trapping equipment and net tows conducted by hand in 2 layers, one above the traps and one immediately below the traps. Trapping equipment consisted of 2 separate instruments: 'Z-traps' to collect individuals migrating downward and 'plummet nets' to collect those migrating upward. The trapping equipment essentially consists of vertically oriented zooplankton nets deployed such that they remain at a specific depth for a period of time to capture individuals moving into them, instead of being towed through the water to collect individuals from a particular depth interval. The Z-traps were paired Bé nets (Bé 1962) with a $0.25 \mathrm{~m}^{2}$ square-shaped opening fitted with $200 \mu \mathrm{m}$ mesh. The plummet net is a vertical closing ring net (King 1979, Miller et al. 1984) with a $1 \mathrm{~m}$ mouth diameter opening and $500 \mu \mathrm{m}$ mesh, which was deployed so that its mouth opening faced downward. Both traps were deployed simultaneously on separate winches over the stern quarters on the starboard (plummet net) and port (Z-traps) sides of the boat. The open end of each net type was deployed to the same depth horizon. Because of their orientation, Z-traps were deployed open and then closed at the end of a deployment, whereas plummet nets were deployed closed, opened at depth, and closed again at the end of the deployment. Closing $60 \mathrm{~cm}$ diameter ring nets fitted with $200 \mu \mathrm{m}$ mesh were used for the vertical net tows. For these deployments, the nets were lowered vertically, with the net opening facing upward, so that they would not collect individuals during descent. Once the deepest depth of the sample interval was reached, the net was towed upward to the shallowest sample depth, and the net was closed with a messenger and retrieved. Depths for these net tows were selected so that one sample interval encompassed the trapping depth to surface, while the upper end of the other sample interval was the trapping depth, and encompassed a similar total vertical extent as the upper net. One complete trapping series was completed in an hour, which allowed 
us time to deploy the traps, collect net samples, recover the traps after $45 \mathrm{~min}$, and rig the traps and nets for the next series. Trap series were scheduled to begin just before dusk to bracket the upward and downward DVM of copepods and continue through the night depending on conditions, with 4 to 9 trap series completed on a given night (Table 1). The Ztraps and plummet nets were also tested on most cruises to make sure that the instruments were not sampling during deployment and recovery (Pierson et al. 2009, J. J. Pierson unpubl. data); this was accomplished by simply deploying each instrument to the sample depth, closing the net, recovering it immediately, and counting the number of individuals that were sampled during that process.

In addition to the trapping program, we also took 4 vertically stratified net tows to a maximum depth of $160 \mathrm{~m}$ near midday and midnight on the summer 2007 and spring 2008 cruises (Table 1). On the spring 2007 cruise, we completed a midday series of vertical net tows to $160 \mathrm{~m}$ but not at midnight. On that cruise, we took 4 tows in the upper $40 \mathrm{~m}$ at midnight to assess the small-scale variability of zooplankton in the upper water column. In autumn 2007, we did not take a daytime series of net tows due to mechanical problems but instead took 4 stratified tows to a maximum depth of $160 \mathrm{~m}$.

\section{Measurements of individuals}

To examine the variability of individuals migrating in different directions or caught in different layers, we sorted individuals from traps after the instruments were recovered and performed several analyses on these individuals. On 3 of the cruises, we also sorted individuals from the hand-hauled net tows in each layer during certain trapping series (Table 1). To do this, the codends from each trapping instrument were removed immediately upon recovery and brought into the ship's lab. Individual female Calanus pacificus and Metridia pacifica (9 to 12 per sample) were sorted from each instrument during each trap series. These individuals were placed on a depression slide and digitally photographed for morphological and gut fullness measurements (Tackx et al. 1995, Pierson et al. 2009). After being photographed, individuals ( $\mathrm{n}=244$ to 399 per cruise) were then immediately placed individually in $1.1 \mathrm{ml}$ of $90 \%$ acetone in cryovials to extract chl a to fluorescently determine the concentration of gut pigments (Arar \& Collins 1997). This measure of gut fluorescence was then related to the gut fullness measures from the digital photographs. Due to the time constraints of sorting individuals and preparing them for analysis, we were only able to sort from either the traps or the nets on any given night, and we were only able to sort females of these 2 species. Sorting and placement in acetone vials for extraction following a given trap series were always completed before initiation of the subsequent trap series; thus, individuals were placed in acetone within $1 \mathrm{~h}$ of capture and often in less than $30 \mathrm{~min}$. To minimize the time between capture and extraction, 2 individuals were sorted at any given time, one from the sample collected with the Z-traps and one from the sample collected with the plummet net. For consistency between samples, C. pacificus was always sorted first, with $M$. pacifica sorted second. On those cruises when we sorted individuals from nets, we did that on the second night of the cruise, after we had already sorted individuals from the traps. Whenever we were sorting individuals from an instrument (e.g. the traps), the samples from the other instrument (e.g. the nets) were preserved immediately.

The digital images of individuals were used to make measurements of both prosome length and gut fullness on each individual adult female using ImageJ software (Rasband 1997-2012). To determine if individual female sizes differed for individuals migrating in different directions or from different layers, we compared prosome length measurements for individuals caught migrating in different directions from the traps or in different layers from the nets. In addition, we compared the length measurements made over time for each night of sampling to determine whether sizes of individuals in given layers or those moving in different directions varied over time. Gut fullness measurements were made by visually outlining the pigmented contents of the gut on each digital image; the software calculated the area within the outline.

\section{Measurements of populations}

Preserved zooplankton samples from the nets and traps were used to estimate the number of individuals migrating into or out of the surface mixed layer using methods described in Pierson et al. (2009). We developed an equation to estimate the flux rate of individuals into the surface layer in terms of the number of individuals per cubic meter per hour, described in detail in Pierson et al. (2009). The equation uses the abundance of individuals per cubic meter in the upper layer before $\left(N_{\mathrm{i}}\right)$ and after $\left(N_{\mathrm{f}}\right)$ a 
trap deployment, the time in hours between those samples $\left(t_{\text {nets }}\right)$, the abundance of individuals per square meter caught migrating downward into the Ztraps $(Z)$, the duration in hours of the trap deployment $\left(t_{\text {traps }}\right)$, and the depth in meters of the traps $(D)$ :

$$
\text { Flux }=\frac{\left(N_{\mathrm{f}}-N_{\mathrm{i}}\right)}{t_{\text {nets }}}-\frac{Z}{D \times t_{\text {traps }}}
$$

This flux calculation was applied to every trap series for which there were sufficient data. To estimate the turnover of the surface mixed layer $\left(\mathrm{h}^{-1}\right.$, 'percent migrating' in Pierson et al. 2009) for the duration of a given trap series, we divided the flux measurements by the mean concentration $\left(\mathrm{m}^{-3}\right)$ in the surface layer $\left[\left(N_{\mathrm{i}}+N_{\mathrm{f}}\right) / 2\right]$.

\section{Statistical analysis}

We used 2-way analysis of variance (ANOVA) tests to determine whether there were significant differences $(p<0.05)$ between the direction of migration or the time of trap series for the 3 variables (gut fluorescence, individual prosome length, and gut fullness). Separate tests were performed for each variable on each cruise and for each species. Linear regressions of the relationship between gut fluorescence and gut fullness were calculated, and the results were used to create a linear model to estimate the amount of chl a in guts of individuals for which we have gut fullness measurements but no gut fluorescence measurements. All statistical tests were done in MATLAB using Statistics Toolbox (Mathworks).

\section{RESULTS}

\section{Hydrographic conditions}

We conducted 4 cruises in 3 different seasons: spring 2007 and 2008, summer 2007, and autumn 2007. These cruises differed in the physical structure of the water column as well as in the vertical distribution of chl a (Table 1, Fig. 1). Here, we only present hydrographic data collected in the upper $50 \mathrm{~m}$ because it is the region of interest for our study, even though the CTD was deployed to within $3 \mathrm{~m}$ of the bottom at least once on each cruise (data were submitted to the National Oceanographic Data Center, accession number 0041970). In general, temperature maxima occurred at the surface on all cruises, with warmest temperatures in the summer 2007 cruise

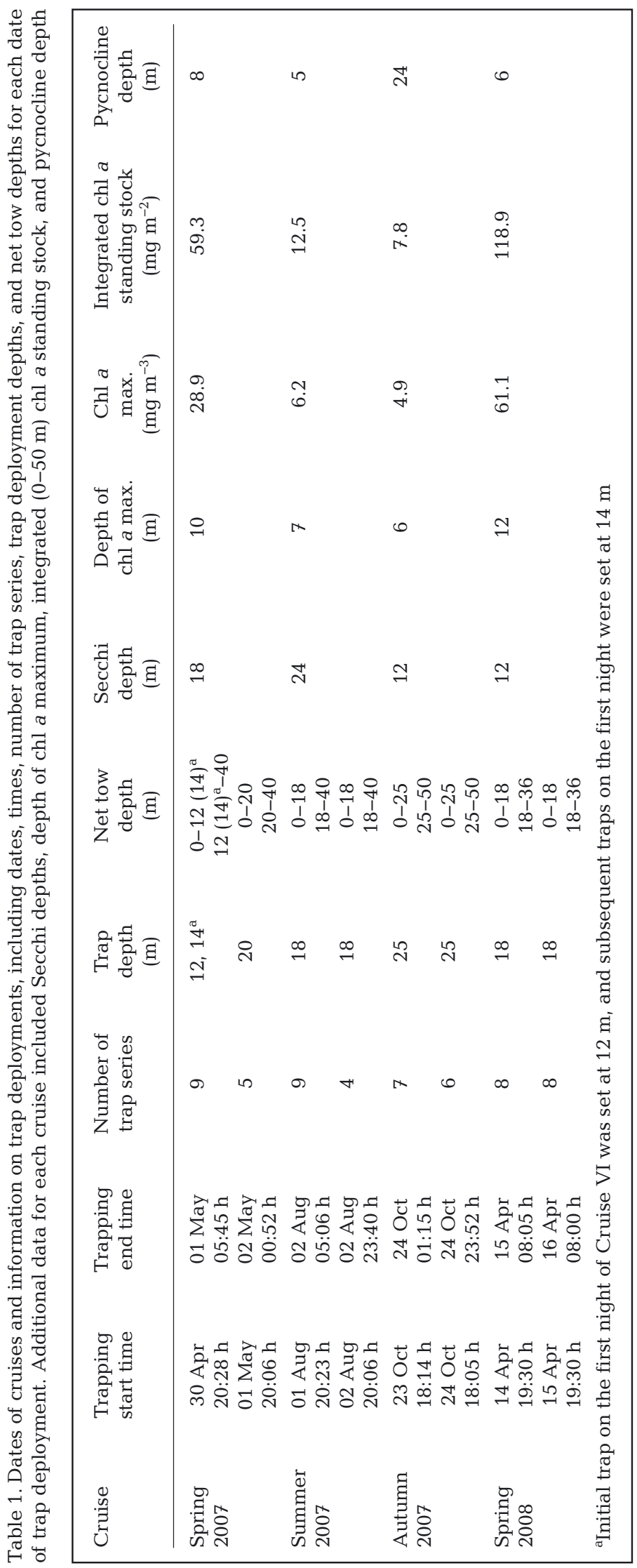




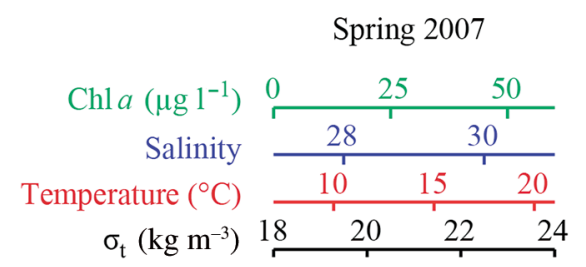

\begin{tabular}{ccccc}
\multicolumn{5}{c}{ Summer 2007} \\
0 & & 25 & \multicolumn{2}{c}{50} \\
\hline & 28 & & \multicolumn{2}{c}{30} \\
\hline & 30 & \\
\hline & 10 & 15 & 20 \\
\hline 18 & 20 & 22 & 24 \\
\hline
\end{tabular}

\begin{tabular}{|c|c|c|c|}
\hline & \multicolumn{3}{|c|}{ Autumn 2007} \\
\hline 0 & 2 & & \\
\hline & 28 & 3 & \\
\hline & 10 & 15 & 20 \\
\hline 18 & 20 & 22 & 24 \\
\hline
\end{tabular}

\begin{tabular}{|c|c|c|c|}
\hline & \multicolumn{3}{|c|}{ Spring 2008} \\
\hline 0 & 2 & & 0 \\
\hline & $28^{1}$ & & \\
\hline & 10 & 15 & 20 \\
\hline 18 & 20 & 22 & 24 \\
\hline
\end{tabular}
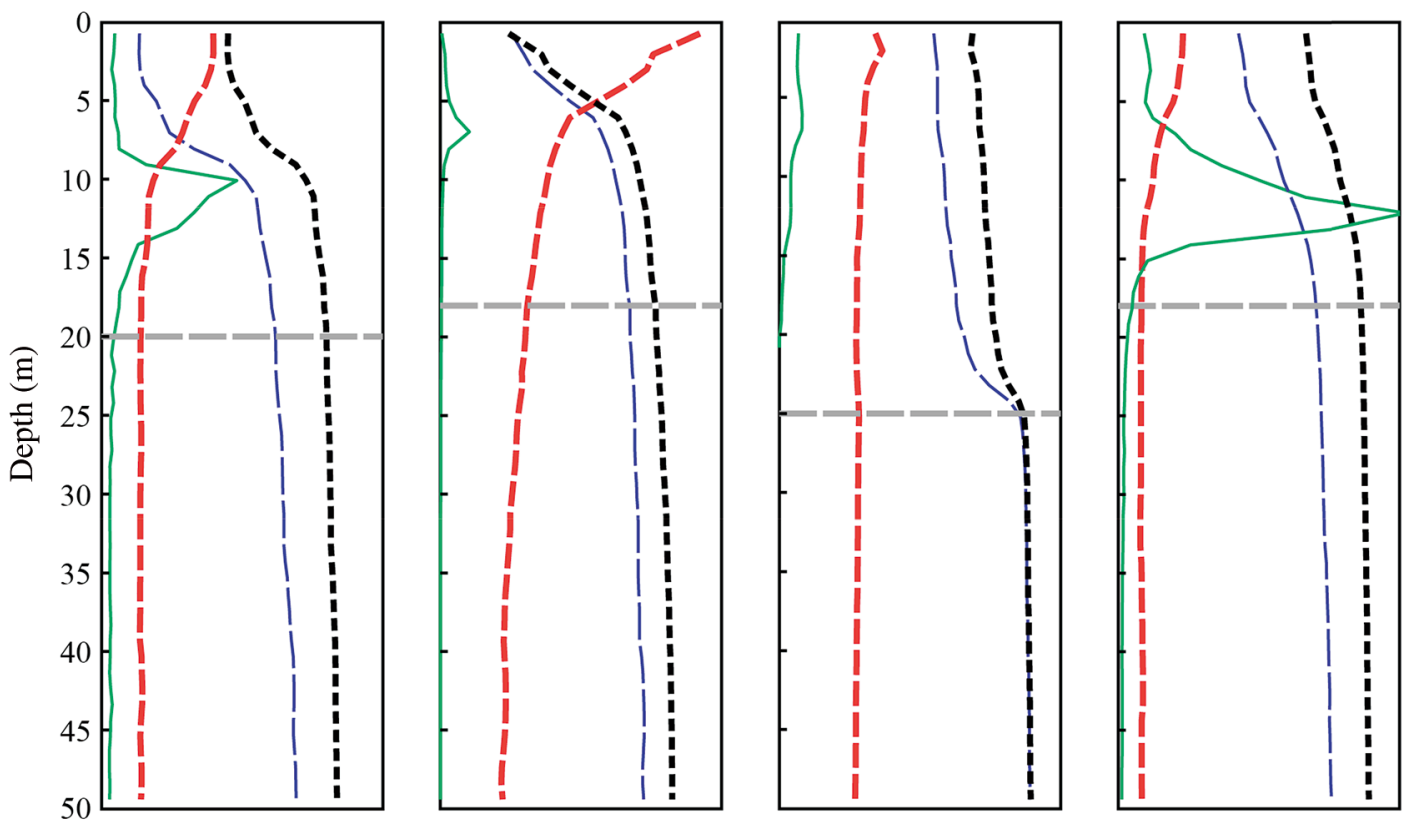

Fig. 1. CTD profiles from the first CTD cast on each cruise showing chl a concentration, salinity, temperature, and density profiles $\left(\sigma_{t}\right)$. Horizontal scales for each variable are the same for all plots; horizontal grey dashed lines show trap deployment depths on the first night of each cruise

$\left(19.9^{\circ} \mathrm{C}\right)$ and coldest temperatures in the spring 2008 cruise $\left(10.2^{\circ} \mathrm{C}\right)$. Salinity varied by a maximum of 2 units in the upper $50 \mathrm{~m}$ on all cruises, with lowest surface minima in spring 2007 (27.5) and highest surface maxima in autumn 2007 (30.5). The depth of the pycnocline coincided with thermoclines and haloclines except in the autumn 2007 cruise, when density changes were driven entirely by salinity variation due to small vertical temperature differences. Chl a vertical distribution was highly variable between the cruises in terms of pattern and standing stock. The 2 spring and 1 summer cruises had subsurface chl a maxima centered between 7 and $15 \mathrm{~m}$, which were always associated with a pycnocline. The summer and autumn cruises in 2007 had the lowest integrated ( 0 to $50 \mathrm{~m}$ ) chl a values (12.5 and $7.8 \mathrm{mg}$ $\mathrm{m}^{-2}$, respectively). In autumn 2007, chl a was elevated in the upper $15 \mathrm{~m}$ compared to deeper values, but it was still much lower than in either of the spring cruises and had no discernible peak. Highest standing stock was observed in the 2 spring cruises; however, integrated chl a values were 2 times higher in $2008\left(118.9 \mathrm{mg} \mathrm{m}^{-2}\right)$ than in $2007\left(59.3 \mathrm{mg} \mathrm{m}^{-2}\right)$.

\section{Copepod abundance and vertical distribution}

Integrated abundance and vertical distribution varied seasonally (Fig. 2), with an abundance peak in autumn 2007 for both Calanus pacificus $\left(3604 \mathrm{~m}^{-2}\right)$ and Metridia pacifica $\left(17785 \mathrm{~m}^{-2}\right)$ and minima for both species during the spring cruises $\left(230 \mathrm{~m}^{-2}\right.$ for $C$. pacificus and 734 for M. pacifica). On all cruises, $M$. pacifica was 2 to 5 times more abundant than C. pacificus, but the seasonal patterns were similar for both species. There were small differences in abundance between samples taken during the day and at night for each taxon.

Vertical distribution and DVM patterns varied between seasons and species. Calanus pacificus showed a strong DVM pattern in spring and summer 2007. In spring 2008, there was a shift of individuals to the upper $18 \mathrm{~m}$ at night, suggesting DVM, but the population maximum was found in the 18 to $36 \mathrm{~m}$ layer during the day. Metridia pacifica showed strong DVM in spring and summer 2007 as well as in spring 2008; however, the center of mass during the day varied from below $100 \mathrm{~m}$ in 
summer 2007 to $40-80 \mathrm{~m}$ in spring 2007 and 2008. In autumn 2007, we did not have daytime samples, so we cannot make observations about DVM from this cruise; however, the nighttime vertical distribution differed between C. pacificus and M. pacifica, with the bulk of the $M$. pacifica population below $100 \mathrm{~m}$ and the bulk of the $C$. pacificus population above $25 \mathrm{~m}$.

The concentrations of individuals in the layers above (surface) and below (deep) the trap deployment interval are shown in Fig. 3. In spring 2007 and 2008, Calanus pacificus abundance was higher in the deep layer, except for 02:00 to 06:00 $\mathrm{h}$ on the first night in spring 2007 and 06:00 h on the first night in 2008. In summer and autumn 2007, C. pacificus was more abundant in the surface layer at nearly all sampling times. Metridia pacifica distributions varied more than $C$. pacificus distributions, and in most cases, the surface layer abundance was higher than the deep layer abundance earlier each night. The temporal patterns of integrated abundance of the surface and deep layers differed between the species; C. pacificus seemed to ascend to these layers before $M$. pacifica on nearly all occasions. This is supported by the fact that $M$. pacifica often reached maximum nighttime abundance in the upper 2 layers 2 to $4 \mathrm{~h}$ after C. pacificus, except in autumn 2007, when they reached maximum abundance at approximately the same time.

\section{Copepod trap catches and flux estimates}

Trap catches varied widely for both Calanus pacificus and Metridia pacifica within and between cruises (Fig. 4). In general, in spring 2007 and 2008, more
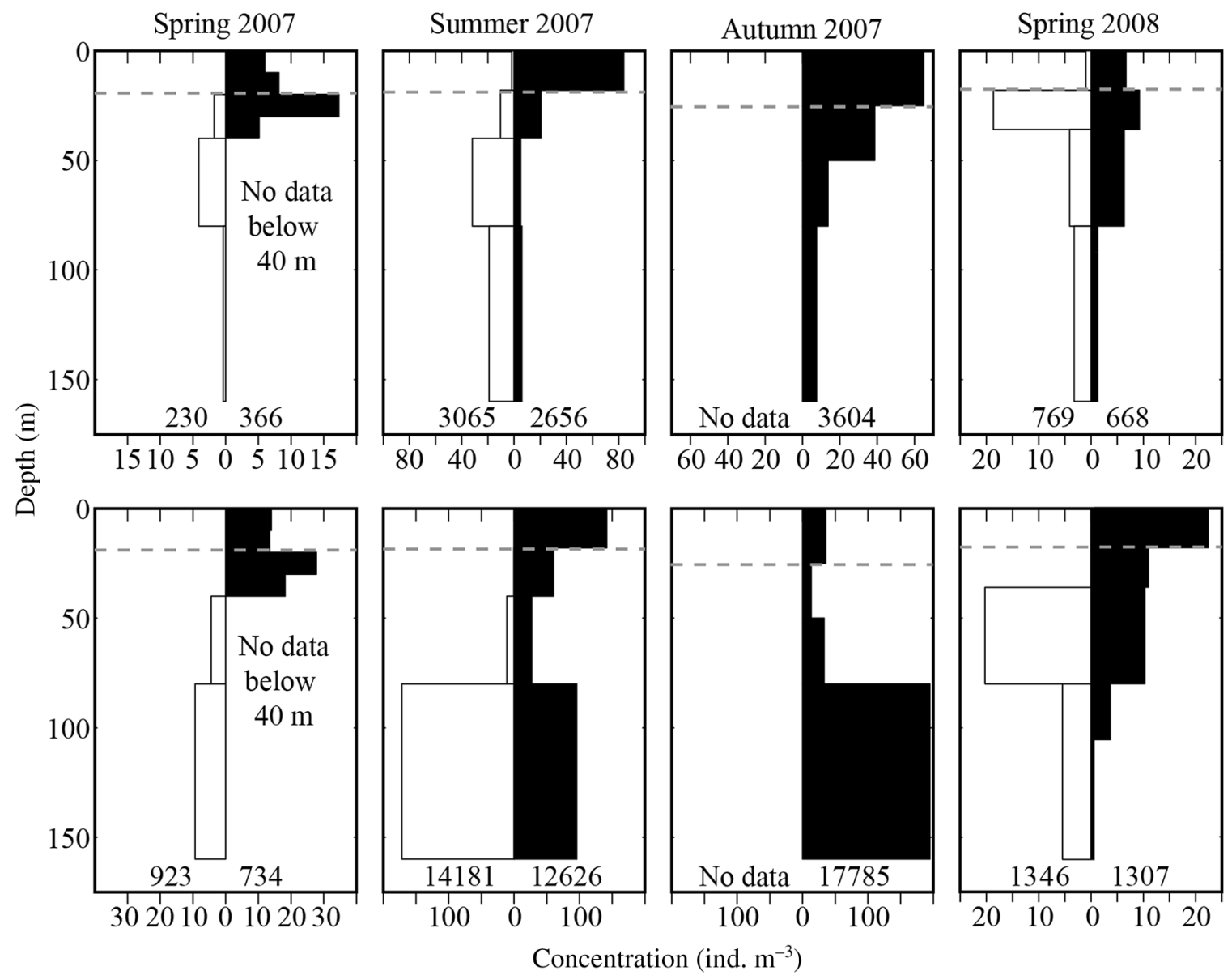

Fig. 2. Calanus pacificus (upper panels) and Metridia pacifica (lower panels). Day (white bars) and night (black bars) vertical distributions of females for each cruise. Width of each bar shows the concentration of females, and the vertical extent of each bar shows the depth distribution. Total mean water column abundance $\left(\mathrm{m}^{-2}\right)$ of triplicate vertical series is shown at the bottom of each panel for day and night samples. In spring 2007, nighttime tows were not deeper than 40 m. Horizontal grey dashed lines show trap deployment depths 

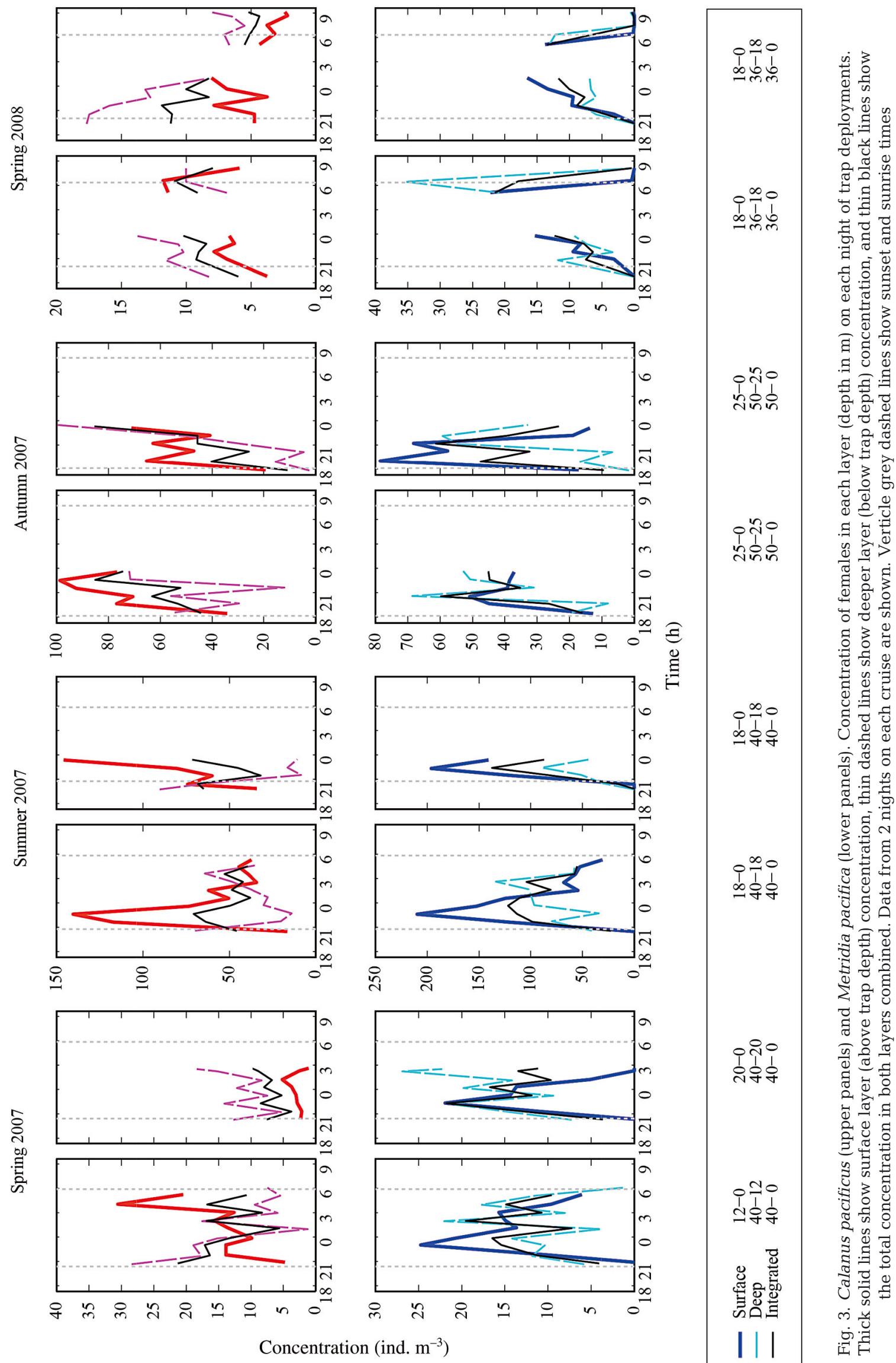

Concentration (ind. $\mathrm{m}^{-3}$ ) 

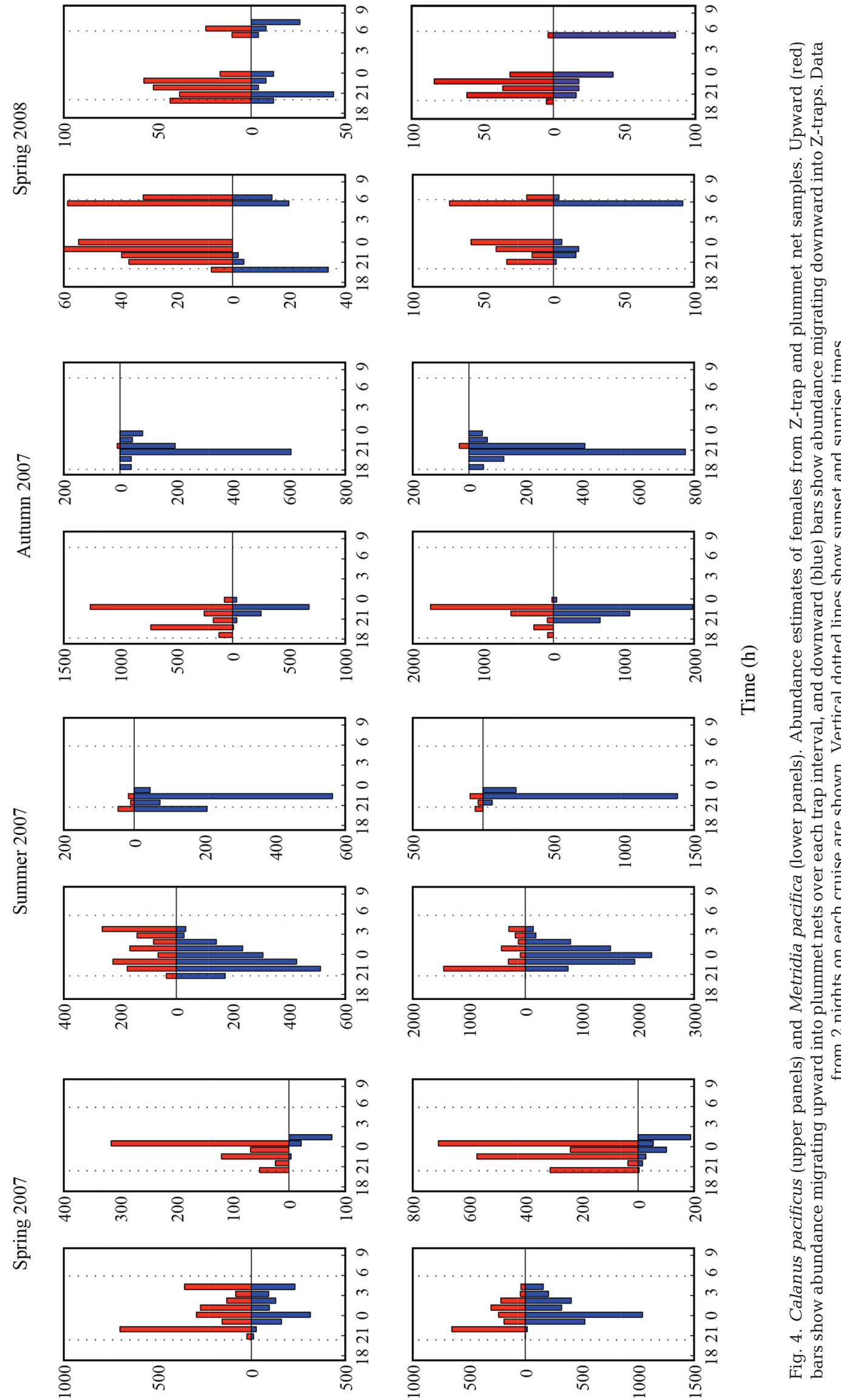

气

Trap abundance (ind. $\mathrm{m}^{-2}$ ) 
individuals were caught migrating upward than downward for both species. Exceptions to this were on the first night of the cruise in spring 2007 for $M$. pacifica and for a few time periods for both species on each cruise in spring 2007 and 2008. In summer 2007, more individuals were caught migrating downward throughout the trapping series for both species, except near dawn on the first night of the cruises. Autumn 2007 data were more varied between nights, with almost no individuals caught migrating upward on the second night of that cruise.

Using Eq. (1) and data from the net tows in the upper 2 layers and trap abundances, we calculated the flux of individuals into the surface layer (data not shown, see Fig. S1 in the supplement at www.int-res. com/articles/suppl/m475p049_supp.pdf). The results varied widely between and within cruises, as well as between species, with few clear patterns emerging. On some cruises, we were able to observe a large influx of individuals into the surface layer, apparently at the beginning of DVM behavior. On some cruises, we also observed a downward flux into the deeper water near dawn, presumably the termination of the surface phase of the DVM behavior. However, data throughout the night showed some periods of large downward fluxes for both species, with periods of smaller upward fluxes; the timing of maximum flux varied between nights, with no clear patterns. Flux rates for Metridia pacifica were nearly always higher than those for Calanus pacificus.

We divided the flux by the average abundance in the surface layer during the period of trap deployment to estimate the percent of individuals in the surface layer that are migrating. An alternative interpretation of this calculation is that it is a turnover rate $\left(\mathrm{h}^{-1}\right)$ of the surface layer during the trapping interval (Fig. 5). These values varied widely between cruises and species. Highest turnover rates occurred in summer and autumn 2007, with up to $1000 \%$ of the surface layer migrating at various times of the night for each species. This was generally observed before midnight, or shortly after the population ascended for DVM. In spring 2007 and 2008 , at least $100 \%$ of the surface layer population for both species migrated on each night at some point, except for the first night in 2008, when no more than $60 \%$ of Calanus pacificus migrated to or from the surface layer at any time. On average, the magnitude of both the flux and turnover rates were higher for both species in summer and autumn than during the 2 spring cruises, with higher flux and turnover rates coinciding with periods of lower chl $a$.

\section{Length and gut contents of individual copepods}

Individual copepods were sorted from traps and net tows when possible, and prosome length, gut fluorescence, and gut fullness were measured from 9 to 12 individuals of each species for each direction (traps) or layer (nets) during each trap series. A 2way ANOVA on length measurements was made on each cruise and for each gear type (Table 2) and showed no clear pattern in length variation by trap time or direction among cruises. The seasonal variation in sizes followed a similar pattern for both species, with the largest females found in spring 2007 and 2008 and the smallest individuals found in summer 2007 (Fig. 6). Copepods caught in autumn were larger than those caught in summer, and for Metridia pacifica there was no statistical difference in prosome lengths of females in summer and autumn 2007 (Tukey's HSD post-hoc test).

Gut contents in individuals were estimated using both gut fluorescence and image analysis techniques. We regressed the gut area estimates against the chl a gut fluorescence and found significant relationships for both Calanus pacificus $(y=0.0107 x+$ 0.0133, $\left.\mathrm{p}<0.0001, \mathrm{r}^{2}=0.31, \mathrm{n}=777\right)$ and Metridia pacifica $\left(y=0.0100 x+0.2327, p<0.0001, r^{2}=0.37, n\right.$ $=687$ ). We ran all statistical tests with raw data as well as data normalized to sizes and found no differences in the results of the statistical tests between raw and normalized data, so we used the raw data for all statistical tests and plots. Seasonal patterns from both methods were similar, with the highest individual gut fullness values in spring 2007 and 2008 for C. pacificus and in spring 2007 for M. pacifica (see Figs. S2 \& S3 in the supplement at www.int-res.com/ articles/suppl/m475p049_supp.pdf). Gut contents of C. pacificus were lowest in summer and autumn

Table 2. p-values from 2-way ANOVA tests, performed on data from each cruise and collection method, to determine whether individual length varied by trap series or direction. Significant values in bold

\begin{tabular}{|lcccc|}
\hline & \multicolumn{2}{c}{ Spring } & \multicolumn{3}{c}{ Summer } & Autumn & Spring \\
& 2007 & 2007 & 2007 & 2008 \\
\hline Calanus pacificus & & & & \\
$\begin{array}{l}\text { Trap time } \\
\text { Direction }\end{array}$ & $\mathbf{0 . 0 0 5}$ & 0.682 & $\mathbf{0 . 0 2 3}$ & 0.349 \\
$\begin{array}{l}\text { Trap time } \times \text { Direction } \\
\text { Metridia pacifica }\end{array}$ & 0.195 & 0.063 & $\mathbf{0 . 0 3 9}$ & 0.611 \\
$\begin{array}{l}\text { Trap time } \\
\text { Direction }\end{array}$ & $\mathbf{0 . 0 0 3}$ & 0.361 & 0.071 & 0.684 \\
Trap time $\times$ Direction & 0.582 & 0.675 & 0.482 & 0.519 \\
& 0.675 & 0.942 & 0.450 & 0.247 \\
\hline
\end{tabular}



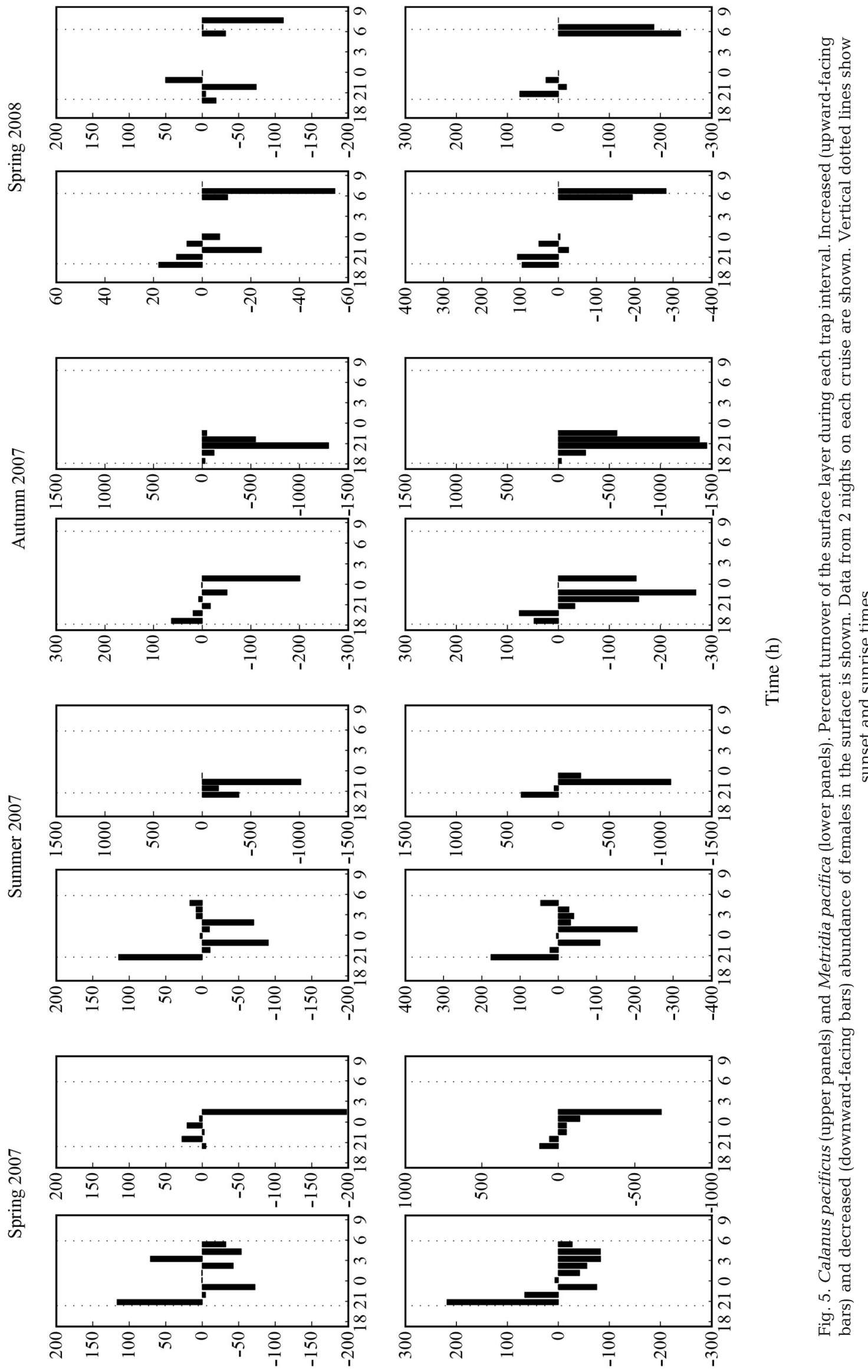

Percent turnover of the surface layer 


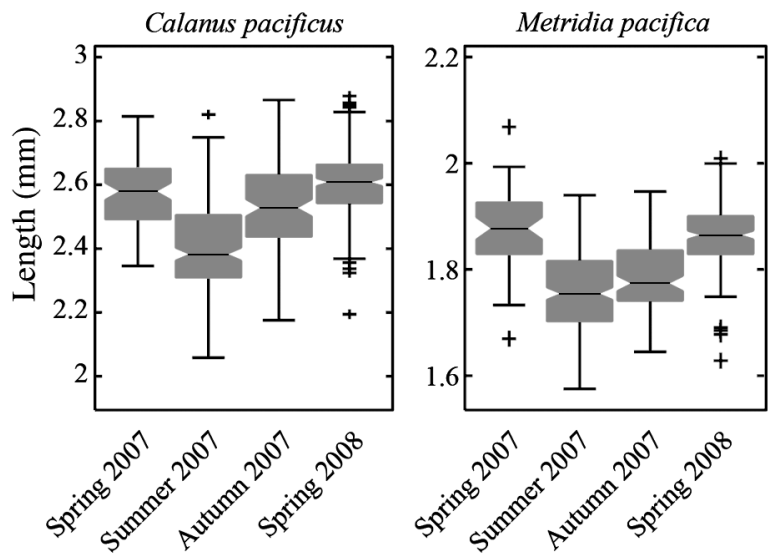

Fig. 6. Calanus pacificus (left panel) and Metridia pacifica (right panel). Prosome lengths of all females imaged from nets and traps on each cruise. Boxes show interquartile range, horizontal bars show median, notches show the $95 \%$ confidence interval of the median, whiskers show the range of data, and crosses show outliers

(Fig. 7; Figs. S2 \& S3 in the supplement). M. pacifica had lowest gut contents in autumn 2007. To determine if gut contents varied between trap time and direction, we performed 2-way ANOVAs without interaction effects on the gut fluorescence and gut fullness data from each cruise. There were no discernible patterns in significant $(p<0.05)$ differences between trap time of deployment or direction across cruises, between species, or for the different variables (Table 3). Statistically significant differences ( $p<0.05$ ) of gut chl a content for C. pacificus were observed on 2 occasions for each factor (trap time and direction) and for the interaction of the 2 factors. Statistically significant results of gut fullness area for C. pacificus were observed 4 times for trap time, 3 times for direction, and twice for the interaction of the two. For M. pacifica, gut chl a was found to be statistically significant 4 times for trap time, 3 times for direction, and once for the interaction of those factors, whereas for gut fullness area, statistical significance was found 3 times for trap time, never for direction, and twice for interaction of the 2 factors. Pooling all of the data for each species showed that gut fluorescence was significantly higher for individuals migrating downward than for those migrating upward for both $C$. pacificus (2-sample $t$-test, $\mathrm{p}=$ 0.0169 ) and M. pacifica (2-sample $t$-test, $\mathrm{p}=0.0014$ ). Gut fullness area was not significantly different for individuals migrating in different directions for either species (2-sample $t$-test, $\mathrm{p}=0.2146$ for C. pacificus, $\mathrm{p}=0.3254$ for $M$. pacifica).

\section{DISCUSSION}

Pearre (2003) reviewed the literature on the 'hunger/satiation hypothesis' (HSH), which states that vertical migration is driven by a cycle of hunger and satiation, where individuals rise from depth at dusk to feed and return to depth once sated. Observations supporting HSH often rely on observations from acoustics or vertically stratified net tows as well as observations of gut contents of individuals in various layers (Pearre 2003). HSH may be imposed on normal DVM and be used to explain 'midnight sinking' by Calanus finmarchicus, a congener of C. pacificus (e.g. Simard et al. 1985). Midnight sinking has also been attributed to predator avoidance behavior (Tarling et al. 2002, 2003); however, those observations have also been interpreted in different ways (Pearre 2003). Our study did not measure predation;

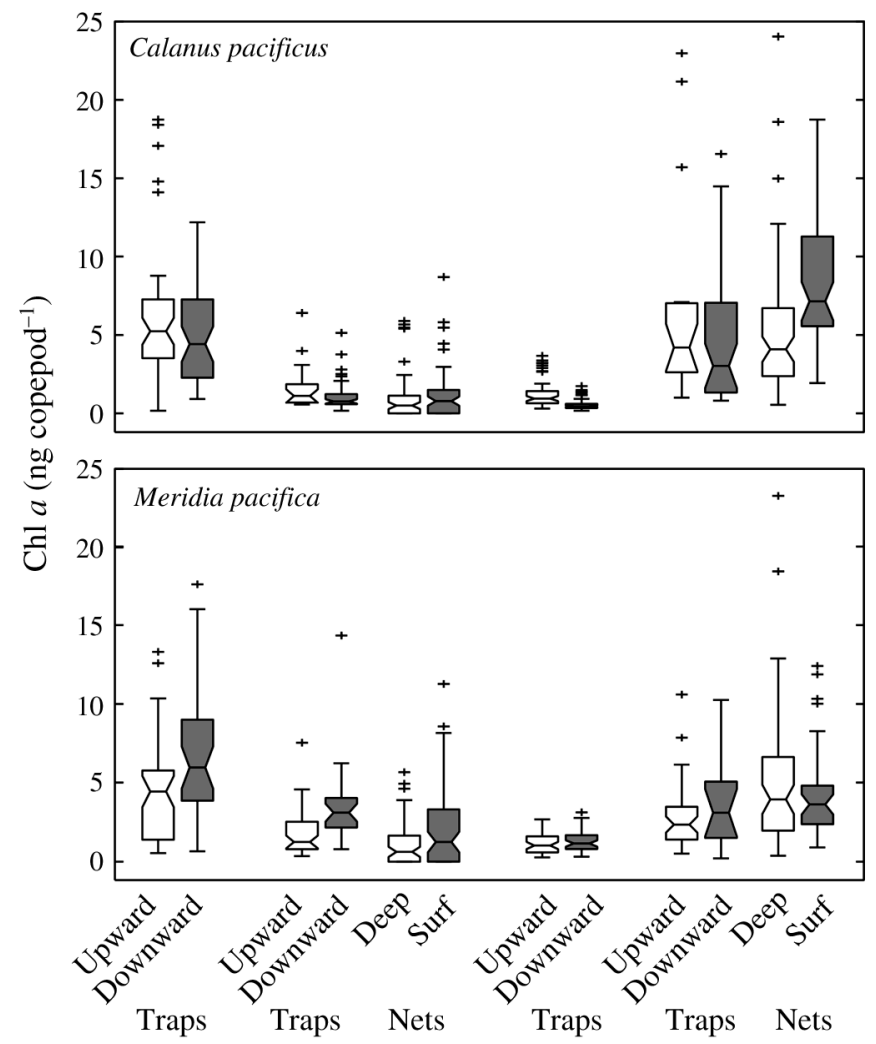

Spring 2007 Summer 2007 Autumn 2007 Spring 2008

Fig. 7. Calanus pacificus (upper panel) and Metridia pacifica (lower panel). Gut contents of individual females from trap series (Traps; Z-traps [grey boxes, Downward] and plummet nets [white boxes, Upward]) and net series (Nets; layer above traps [grey boxes, Surf] and layer below the traps [white boxes, Deep]). Boxes show interquartile range, horizontal lines show median, notches show the $95 \%$ confidence interval of the median, whiskers show $95 \%$ of the range of data, and crosses show outliers 
Table 3. p-values from 2-way ANOVA tests, performed on data from each cruise and collection method, to determine whether gut chl a or gut fullness area varied by trap series or direction. Significant values in bold

\begin{tabular}{|c|c|c|c|c|c|c|c|}
\hline & \multirow{2}{*}{$\begin{array}{c}\text { Spring } 2007 \\
\text { Trap }\end{array}$} & \multicolumn{2}{|c|}{ Summer 2007} & \multicolumn{2}{|c|}{ Autumn 2007} & \multicolumn{2}{|c|}{ Spring 2008} \\
\hline & & Trap & Net & Trap & Net & Trap & Net \\
\hline \multicolumn{8}{|l|}{ Gut chl a } \\
\hline \multicolumn{8}{|l|}{ Calanus pacificus } \\
\hline Trap time & 0.053 & 0.007 & 0.012 & 0.139 & - & 0.276 & 0.451 \\
\hline Direction & 0.129 & 0.832 & 0.210 & 0.000 & - & 0.090 & 0.000 \\
\hline Trap time $\times$ Direction & 0.637 & 0.084 & 0.049 & 0.080 & - & 0.018 & 0.083 \\
\hline \multicolumn{8}{|l|}{ Metridia pacifica } \\
\hline Trap time & 1.000 & 0.002 & 0.000 & 0.000 & - & 0.043 & 0.403 \\
\hline Direction & 0.002 & 0.031 & 0.000 & 0.102 & - & 0.854 & 0.710 \\
\hline Trap time $\times$ Direction & 0.124 & 0.540 & 0.004 & 0.867 & - & 0.979 & 0.704 \\
\hline \multicolumn{8}{|l|}{ Gut fullness area } \\
\hline \multicolumn{8}{|l|}{ Calanus pacificus } \\
\hline Trap time & 0.000 & 0.120 & 0.029 & 0.019 & 0.031 & 0.049 & 0.097 \\
\hline Direction & 0.730 & 0.327 & 0.955 & 0.023 & 0.004 & 0.074 & 0.008 \\
\hline Trap time $\times$ Direction & 0.113 & 0.951 & 0.003 & 0.188 & 0.014 & 0.391 & 0.570 \\
\hline \multicolumn{8}{|l|}{ Metridia pacifica } \\
\hline Trap time & 0.937 & 0.024 & 0.000 & 0.259 & 0.050 & 0.149 & 0.000 \\
\hline Direction & 0.637 & 0.361 & 0.488 & 0.271 & 0.529 & 0.061 & 0.822 \\
\hline Trap time $\times$ Direction & 0.003 & 0.965 & 0.105 & 0.942 & 0.004 & 0.693 & 0.596 \\
\hline
\end{tabular}

our intent was to determine the seasonal variability in the foray foraging behavior. It is likely that some aspect of the migratory behavior of both species was impacted by predation. Fish predation has been shown to affect DVM for C. pacificus in Dabob Bay (Bollens \& Frost 1989), but the stronger DVM observed for Metridia pacifica was not attributed to greater predation pressure (cf. M. lucens, Bollens et al. 1993). Our observations are of a behavior that is superimposed on DVM and, thus, would not be captured by the methods used in those earlier studies.

The foray foraging hypothesis is an adaptation of $\mathrm{HSH}$, in that we suggest individuals ascend synchronously to surface waters at dusk, cued by light. Individual zooplankton feed there until sated and then descend to layers just below the food-rich surface to avoid predation; the depth of this descent is not nearly as deep as daytime depths. After some refractory digestive period, the copepods ascend into the food-rich layers again to feed and repeat the cycle in an effort to balance ingestion with predation risk. These subsequent short migrations that occur throughout the night are hypothesized to be asynchronous but are followed by a generally synchronous descent to daytime depths at dawn. Numerical simulations suggested that the most likely means of detecting the presence of foray behavior was by observing differences in the gut contents of individuals moving in different direc- tions, not using abundance data collected from nets as is typically done to study DVM (Leising et al. 2005). In those simulations, abundances from trap catches were also not able to unambiguously discern the foray behavior from individuals that had a random swimming motion once sated, but they did not include flux estimates as described by Pierson et al. (2009) to determine the rate of turnover from those data.

In only a few instances have zooplankton migration behaviors in situ been directly documented using traps to capture moving zooplankton (Harding et al. 1986, Armengol \& Miracle 2000), and with limited success, particularly for larger copepods such as Calanus spp. Pierson et al. (2009) showed how the traps used in the present study, which are essentially zooplankton nets that remain stationary in the water instead of being towed, could be combined with observations of abundance from net tows to estimate the flux of individuals into and out of the surface layer. That work also showed that individuals captured migrating downward had significantly more $\mathrm{chl} a$ and higher gut fullness (estimated from image analysis) than those migrating upward. Here, we have shown that although these general patterns persist for the 2 copepods C. pacificus and Metridia pacifica, there is strong variability across seasons and between the species. This variability may be related to variability in food concentration. 
The strongest line of evidence supporting the existence of the foray foraging behavior is that copepods have more in their guts when they are captured migrating downward than migrating upward, despite the fact that differences in gut contents between individuals migrating in different directions were not significantly different for every cruise (Table 3). This finding is not surprising, as many factors could have decreased our ability to detect significant differences in gut contents on any particular cruise, such as digestion by individuals while within the net and during sorting, or individuals swimming into the net and becoming entrapped before having time to feed within the surface. Both of these phenomena would decrease our estimate of gut fluorescence of the downward-migrating copepods. Further support for the foray hypothesis is taken from the estimates of flux (data not shown) and percent turnover of the surface layer (Fig. 5), which was termed 'percent migrating' in Pierson et al. (2009). Nightly means of the turnover rates calculated from these data ranged from 17 to $400 \%$ of the population per hour for Calanus pacificus and 68 to $740 \%$ of the population per hour for Metridia pacifica (Fig. 5). Such high turnover rates can only be occurring if the copepods are undergoing these short-term, shortdistance migrations between the layers, consistent with the foray foraging hypothesis. The turnover rates were also highest in summer and autumn for both species, and lowest in spring, while gut contents were highest in spring for both species. This suggests that foray foraging behavior is more prevalent in summer and autumn than in spring for both species. This was an unexpected finding; based on observations of DVM, we initially hypothesized that foray foraging behavior would be strongest in spring for $C$. pacificus and present all year for M. pacifica (Frost 1988, Osgood \& Frost 1994b, Dagg et al. 1998). However, the observed patterns may be related to the amount of available food, predators, or the placement of the traps. Chl a was much higher in spring 2008 than in summer 2007 (Fig. 1), and turnover of the surface layer was lower in spring 2008 than in summer 2007. The overall lower chl $a$ in summer and autumn may have led the copepods to engage in more foray foraging behavior to search for available food, compared to spring, with distinct chl a peaks that may have provided more available food and thus required fewer forays to achieve a daily ration. These patterns may also be linked to search behavior (e.g. Leising \& Franks 2000), but this is unlikely because if that were the case, we would expect to find no differences in gut fullness between individuals moving upward and those moving downward, and our data clearly show that individuals migrating downward have fuller guts than those migrating upward (Table 3, Fig. 7; Pierson et al. 2009). Predation may have differed between seasons, which may also have driven migratory behaviors, but that is beyond the scope of this paper. Additionally, we did not evaluate how trap placement could have affected the results; however, if the traps are not placed in the region of highest migration behavior, the results may vary between cruises or deployments.

Despite the clear evidence of foray foraging behavior, there are some limitations associated with the trapping equipment. As described in Pierson et al. (2009), both Calanus pacificus and Metridia pacifica avoided the plummet net, which was used to capture individuals migrating upward. This was also observed in previous attempts to trap migrating zooplankton (Harding et al. 1986, Armengol \& Miracle 2000). To account for this, we developed methods to quantify the migration of individuals into and out of the surface layer independent of the measurements from the upward migrators (e.g. the flux calculations). The Z-traps appear to capture downward migrators efficiently; the numbers of individuals caught in the traps migrating downward were able to explain decreases in surface layer abundances (data not shown). Another limitation of the equipment is that it did not function efficiently when there were strong currents. In those instances, the Z-traps performed like oblique net tows. To account for this, we disregarded data in which the wire angle rose above $15^{\circ}$, determined using clinometers on the wire. Z-traps and plummet nets were also fitted with temperature depth recorders that recorded changes in depth at 1 s intervals (data not shown), and when the Z-traps or plummet nets made vertical excursions greater than $0.5 \mathrm{~m}$ during the deployment, those data were also discarded. Fortunately this resulted in the loss of very few trap series $(<5 \%)$ over the course of our entire field project.

We found different-sized individuals migrating upward compared to those migrating downward for both species in autumn 2007 (Table 2). The reason for this is unclear, but it may partially be a seasonal effect; the summer and autumn 2007 female size data varied more than the spring 2007 and 2008 data, possibly suggesting different cohorts of females within the population that may have led to varying behaviors. Pierson et al. (2009) showed a similar finding, and those data were collected in autumn 2006. We did, however, observe changes in female size between cruises (Fig. 7), as expected. The largest 
individuals of both species were found in spring, and the smallest were found in summer. This is most likely related to temperature-dependent development and growth rates that can cause individuals to grow larger at lower temperatures (Vidal 1980, Campbell et al. 2001), directly impacting the different generations of individuals sampled during each season.

The findings from this study highlight the variability in short-term behaviors in marine copepods, which may affect interpretations of vertical distribution and migration. For example, foray behavior may affect our understanding of predator impacts on copepods. From the point of view of the predators, a result of the foray behavior may be that the concentration of prey in the surface layer where they feed is lower on average than if the copepods were not displaying foray behavior. Alternatively, as the copepods' first several forays into the surface are more synchronized, predators may go through alternating periods where they are either presented with more prey than they can ingest (super-saturated) or periods when prey concentration falls below a threshold required for adequate feeding. We have shown that the synchrony in foray events breaks down several hours after the initial surface migration, likely due to individual variability in feeding and digestive history. Leising et al. (2005) found in a simulation that foray behavior could lead to both an increased fitness for the copepods and a decreased abundance of prey for the predators. In that simulation, the behavior was not detectable with standard sampling techniques; the foray foraging behavior was observed only by examining the gut contents of individuals collected migrating in different directions.

Foray behavior may also impact the movement of material into and out of the surface mixed layer. Zooplankton may mediate a large portion of vertical carbon flux through release of fecal material and other means (Steinberg et al. 2008). However, most of these measurements average over $24 \mathrm{~h}$ or longer periods. Our observations show that the flux of organisms between the surface mixed layer and the layers below the thermohalocline are possibly 1 to 2 orders of magnitude greater than would be calculated from a single DVM event. Thus material, both ingested and egested, was moving vertically across the shallow pycnocline at much higher rates than previously surmised. Export from the surface mixed layer (below the pycnocline) may affect the fate of the material, as well as the fate of the organisms that are migrating. Integrating the impacts of the observed short-term foray foraging behavior migrations over seasonal time scales and large spatial scales may prove to be an important component to vertical material flux. Future work examining the impacts of this behavior on marine food webs, benthic-pelagic coupling, and oceanic nutrient cycles is imperative and will require novel approaches and measurements on individuals.

Acknowledgements. The authors thank M. Nuwer, J. Postel, and $\mathrm{D}$. Thoreson, who were instrumental in development of the trap systems used here; R. McQuin and N. Hix of the RV 'Clifford A. Barnes' for their support of the work; numerous cruise volunteers, who assisted with the field work; and 3 anonymous reviewers, who provided constructive feedback. This work was supported by National Science Foundation grant OCE-0525943 and is UMCES contribution 4717.

\section{LITERATURE CITED}

Arar EJ, Collins GB (1997) Method 445.0: in vitro determination of chlorophyll $a$ and pheophytin $a$ in marine and freshwater algae by fluorescence. United States Environmental Protection Agency, Office of Research and Development, National Exposure Research Laboratory, Cincinnati, $\mathrm{OH}$

Armengol X, Miracle MR (2000) Diel vertical movements of zooplankton in lake La Cruz (Cuenca, Spain). J Plankton Res 22:1683-1703

Bé AWH (1962) Quantitative multiple opening-and-closing plankton samplers. Deep-Sea Res 9:144-151

> Block BA, Jonsen ID, Jorgensen SJ, Winship AJ, and 17 others (2011) Tracking apex marine predator movements in a dynamic ocean. Nature 475:86-90

$>$ Bollens SM, Frost BW (1989) Zooplanktivorous fish and variable diel vertical migration in the marine planktonic copepod Calanus pacificus. Limnol Oceanogr 34: 1072-1083

Bollens SM, Osgood K, Frost BW, Watts SD (1993) Vertical distributions and susceptibilities to vertebrate predation of the marine copepods Metridia lucens and Calanus pacificus. Limnol Oceanogr 38:1827-1837

Campbell RG, Wagner MM, Teegarden GJ, Boudreau CA, Durbin EG (2001) Growth and development rates of the copepod Calanus finmarchicus reared in the laboratory. Mar Ecol Prog Ser 221:161-183

> Cohen JH, Forward RB (2009) Zooplankton diel vertical migration-a review of proximate control. Oceanogr Mar Biol Annu Rev 47:77-109

$>$ Dagg MJ, Frost BW, Walser WE Jr (1989) Copepod diel migration, feeding, and the vertical flux of pheopigments. Limnol Oceanogr 34:1062-1071

$>$ Dagg MJ, Frost BW, Newton JA (1997) Vertical migration and feeding behavior of Calanus pacificus females during a phytoplankton bloom in Dabob Bay, US. Limnol Oceanogr 42:974-980

> Dagg MJ, Frost BW, Newton J (1998) Diel vertical migration and feeding in adult female Calanus pacificus, Metridia lucens and Pseudocalanus newmani during a spring bloom in Dabob Bay, a fjord in Washington USA. J Mar Syst 15:503-509

Frost BW (1988) Variability and possible adaptive signifi- 
cance of diel vertical migration in Calanus pacificus, a planktonic marine copepod. Bull Mar Sci 43:675-694

Halsband-Lenk C (2005) Metridia pacifica in Dabob Bay, Washington: the diatom effect and the discrepancy between high abundance and low egg production rates. Prog Oceanogr 67:422-441

> Harding GC, Vass WP, Hargrave BT, Pearre S Jr (1986) Diel vertical movements and feeding activity of zooplankton in St. Georges Bay, NS, using net tows and a newly developed passive trap. Can J Fish Aquat Sci 43:952-967

Hays GC, Kennedy H, Frost BW (2001) Individual variability in diel vertical migration of a marine copepod: why some individuals remain at depth when others migrate. Limnol Oceanogr 46:2050-2054

Horner RA, Postel JR, Halsband-Lenk C, Pierson JJ, Pohnert G, Wichard T (2005) Winter-spring phytoplankton blooms in Dabob Bay, Washington. Prog Oceanogr 67: 286-313

King KR (1979) The life history and vertical distribution of the chaetognath, Sagitta elegans, in Dabob Bay, Washington. J Plankton Res 1:153-167

Leising AW, Franks PJS (2000) Copepod vertical distribution within a spatially variable food source: a simple foraging-strategy model. J Plankton Res 22:999-1024

Leising AW, Pierson JJ, Cary S, Frost BW (2005) Copepod foraging and predation risk within the surface layer during night-time feeding forays. J Plankton Res 27: 987-1001

Mackas D, Bohrer R (1976) Fluorescence analysis of zooplankton gut contents and an investigation of diel feeding patterns. J Exp Mar Biol Ecol 25:77-85

Miller CB, Frost BW, Batchelder HP, Clemons MJ, Conway RE (1984) Life histories of large, grazing copepods in a subarctic ocean gyre: Neocalanus plumchrus, Neocalanus cristatus, and Eucalanus bungii in the Northeast Pacific. Prog Oceanogr 13:201-243

Osgood KE, Frost BW (1994a) Comparative life histories of three species of planktonic calanoid copepods in Dabob Bay, Washington. Mar Biol 118:627-636

Osgood KE, Frost BW (1994b) Ontogenic diel vertical migration behaviors of the marine planktonic copepods Calanus pacificus and Metridia lucens. Mar Ecol Prog

Editorial responsibility: Anna Pasternak, Moscow, Russia
Ser 104:13-25

Pearre S (2003) Eat and run? The hunger/satiation hypothesis in vertical migration: history, evidence and consequences. Biol Rev Camb Philos Soc 78:1-79

Pierson JJ, Halsband-Lenk C, Leising AW (2005a) Reproductive success of Calanus pacificus during diatom blooms in Dabob Bay, Washington. Prog Oceanogr 67: 314-331

Pierson JJ, Leising AW, Halsband-Lenk C, Ferm N (2005b) Vertical distribution and abundance of Calanus pacificus and Pseudocalanus newmani in relation to chlorophyll a concentrations in Dabob Bay, Washington. Prog Oceanogr 67:349-365

> Pierson JJ, Frost BW, Thoreson D, Leising AW, Postel JR, Nuwer M (2009) Trapping migrating zooplankton. Limnol Oceanogr Methods 7:334-346

Rasband WS (1997-2012) ImageJ. US National Institutes of Health, Bethesda, MD, available at http://imagej.nih. gov/ij/

Simard Y, Lacroix G, Legendre L (1985) In situ twilight grazing rhythm during diel vertical migrations of a scattering layer of Calanus finmarchicus. Limnol Oceanogr 30: 598-606

Steinberg DK, Van Mooy BAS, Buesseler KO, Boyd PW, Kobari T, Karl DM (2008) Bacterial vs. zooplankton control of sinking particle flux in the ocean's twilight zone. Limnol Oceanogr 53:1327-1338

> Tackx MLM, Zhu L, De Coster W, Billones R, Daro MH (1995) Measuring selectivity of feeding by estuarine copepods using image analysis combined with microscopic and Coulter counting. ICES J Mar Sci 52:419-425

Tarling GA, Jarvis T, Emsley SM, Matthews JBL (2002) Midnight sinking behaviour in Calanus finmarchicus: a response to satiation or krill predation? Mar Ecol Prog Ser 240:183-194

Tarling GA, Jarvis T, Matthews JBL (2003) Calanus finmarchicus descends in response to the arrival of krillbetter unfed than dead. Mar Ecol Prog Ser 252:307-310

Vidal J (1980) Physioecology of zooplankton. I. Effects of phytoplankton concentration, temperature, and body size on the growth rate of Calanus pacificus and Pseudocalanus sp. Mar Biol 56:111-134

Submitted: April 2, 2012; Accepted: October 12, 2012

Proofs received from author(s): January 24, 2013 